Actualidades en Psicología, 29(119), 2015, 43-62

ISSN 2215-3535

http://revistas.ucr.ac.cr/index.php/actualidades

DOI: http://dx.doi.org/10.15517/ap.v29i119.18850

\title{
Modelos de variables latentes, modelación cognitiva y memoria de trabajo: un punto de encuentro
}

\author{
Latent Variable Models, Cognitive Modelling, \\ and Working Memory: a Meeting Point
}

Odir Antonio Rodríguez-Villagra ${ }^{1}$

Universidad de Costa Rica, Costa Rica

\begin{abstract}
Resumen. Los modelos de variables latentes y los modelos cognitivos formales comparten algunos aspectos de su objeto de estudio, varios aspectos filosóficos y parte de su metodología. A pesar de ello, existe poca comunicación entre sus teorías y hallazgos. Con el objetivo de resaltar similitudes y diferencias entre ambos enfoques en este estudio se implementó y evaluó un modelo formal que propone la interferencia entre representaciones como el mecanismo que limita la capacidad de memoria de trabajo (i.e., el modelo de interferencia de Oberauer \& Kliegl, 2006). Además, se incorporó una manipulación experimental que tuvo como objetivo evaluar el papel de la inhibición en respuestas inminentes y el desplazamiento de la atención entre tareas en el contexto del modelo de interferencia. A partir de estos hallazgos se expusieron algunas conexiones que podrían facilitar el acercamiento entre los modelos cognitivos formales y los modelos psicométricos basados en la teoría de la variable latente.
\end{abstract}

Palabras clave. Modelos de variables latentes, modelos cognitivos formales, psicometría y memoria de trabajo.

Abstract. Latent variable models and formal cognitive models share some elements of their object of study, various philosophical aspects, and some parts of their methodology. Nevertheless, little communication exists between their theories and findings. In order to highlight similarities and differences, this study implemented and tested a formal model proposing that interference among representations is a mechanism limiting working memory capacity (i.e., the interference model of Oberauer \& Kliegl, 2006). Furthermore, the study incorporated an experimental manipulation to evaluate the role of the inhibition in prepotent responses and task switching in the interference model framework. These findings were used to expose some connections that could facilitate a rapprochement between formal cognitive models and psychometric models based on the latent variable theory.

Keywords. Latent variable models, formal cognitive models, psychometric, and working memory.

${ }^{1}$ Odir Antonio Rodríguez-Villagra. Instituto de Investigaciones Psicológicas. Centro de Investigación en Neurociencias, Universidad de Costa Rica, Costa Rica. Dirección Postal: 11501-2060, San José. E-mail: odir.rodriguez@ucr.ac.cr

\section{@ $\odot \Theta \Theta$}

Esta obra está bajo una licencia de Creative Commons Reconocimiento-NoComercial-SinObraDerivada 4.0 Internacional. 


\section{Introducción}

La psicometría está relacionada con la implementación, evaluación y sistematización de las prácticas de medición en psicología, educación y ciencias sociales (Psychometric Society, 2015). Un aspecto fundamental de esta área de investigación está asociado con la validez de la interpretación de las puntuaciones que las personas obtienen en un test y su correspondencia con un sistema teóricoempírico de conocimiento (Cronbach \& Meehl, 1955), y las consecuencias sociales de la medición (Messick, 1989). Es claro que los modelos psicométricos son una herramienta útil y necesaria para el estudio de la cognición y el comportamiento humano. A pesar de su importancia varios expertos señalan que la integración de la psicometría en las prácticas de investigación en psicología ha sido insuficiente (Borsboom, 2006; Embretson, 2004) factores pragmáticos, teóricos y sustantivos han sido relacionados con estos problemas de integración (Borsboom, 2006).

Dentro de los aspectos sustantivos se ha señalado que el problema más importante con el que se encuentra la modelación psicométrica es la ausencia de una teoría psicológica poderosa (Borsboom, 2006). A este respecto, Borsboom (2006) señala que a diferencia de los fundadores de la psicometría -Thurstone, Thorndike, Guilford y Kelley- que eran tanto psicólogos como psicometristas, hoy en día, son pocos los psicometristas contemporáneos que demuestran interés por los desarrollos que se dan en las diferentes áreas de la psicología. Así, el desarrollo de los modelos matemáticos queda en manos de los psicometristas y el desarrollo de teorías verbales en manos de los investigadores en psicología. Según dichos autores esto convierte a la psicometría en una disciplina auxiliar que ayuda a la psicología con la formalización de las teorías en modelos estadísticos, que en algunos casos (e.g., la teoría de respuesta a los ítems), son un modelo de medición y, por lo tanto, no contribuyen sustancialmente con la comprensión de los objetos de estudio de la psicología (Borsboom, 2006). Claramente, esto hace que la psicometría resulte menos atractiva para áreas de investigación orientadas al desarrollo y contrastación de teorías.
El objetivo de este artículo es proponer los modelos cognitivos formales como una de las áreas en donde se encuentran numerosas oportunidades para gestar una mejor integración de la psicometría en las prácticas de investigación psicológica. Para ello, se implementa y se contrasta empíricamente un modelo formal sobre los límites de la capacidad de memoria de trabajo. Por un lado, esto ejemplificará como se da el desarrollo de teorías formales en psicología cognitiva y, a su vez, permitirá presentar las similitudes entre la teoría de las variables latentes (Markus \& Borsboom, 2013) y los modelos cognitivos formales.

Por otro lado, la selección de nuestro objeto de estudio, la capacidad de memoria de trabajo, nos permite presentar un campo de conocimiento avanzado con implicaciones sustanciales para el desarrollo de teorías vinculadas con uno de los intereses clásicos y vigentes de la psicometría, a saber, la medición de la inteligencia. Así, en la discusión de este trabajo proponemos cómo hallazgos recientes en el estudio de la memoria de trabajo deberían ser vistos como punto de partida para el desarrollo de teorías psicométricas de la inteligencia que ayuden a dilucidar de mejor manera ésta disciplina científica.

En secciones subsiguientes se define y se justifica la importancia del estudio de memoria de trabajo en la psicología cognitiva, luego se detalla la implementación del modelo de interferencia (MI; Oberauer \& Kliegl, 2006) y, finalmente, se contrasta el MI en una muestra de 20 participantes.

\section{Memoria de trabajo}

La memoria de trabajo permite mantener un subconjunto de representaciones mentales (e.g., localizaciones espaciales, números o palabras) disponibles mientras otro tipo de información o las mismas representaciones son manipuladas con el objetivo de resolver una tarea cognitiva. Diferencias individuales en la capacidad de memoria de trabajo han demostrado ser un buen predictor de la habilidad de razonamiento, inteligencia fluida, y la compresión del lenguaje (Engle, et al., 1999; Kyllonen \& Christal, 1990; Palladino, et al. 2001; Schmiedek, Hildebrant, 
Lövdén, Wilhelm, \& Lindenberger, 2009). Debido a la importancia de la capacidad de la memoria de trabajo en diferentes procesos cognitivos el estudio de los factores que la limitan tiene gran relevancia para la investigación de la cognición humana. Teorías en esta área de investigación difieren en lo que ellas identifican como la principal causa de los límites de la capacidad de memoria de trabajo (Barrouillet \& Camos, 2009; Lewandowsky, Oberauer, \& Brown, 2009). Particularmente, este estudio evalúa la interferencia por sobre escritura como uno de los factores que limita dicha capacidad. La interferencia por sobre escritura se asume que ocurre cuando las representaciones mantenidas en memoria de trabajo comparten algunas de sus características (Oberauer \& Kliegl, 2006).

Adicionalmente, se incorporan dos mecanismos básicos de las funciones ejecutivas: la inhibición de respuestas inminentes y el desplazamiento de la atención entre tareas (Miyake, Friedman, Emerson, Witzki \& Howerter, 2000). La primera se refiere a la habilidad de sostener o prevenir respuestas inminentes pero inapropiadas para una tarea o situación específica (Hasher, Zacks, \& May, 1999). La segunda, refleja la eficiencia y la velocidad de desplazar la atención entre dos diferentes tipos de tareas (Monsell, 2003). De esta manera, acá se investiga cómo estos mecanismos básicos de las funciones ejecutivas afectan la habilidad de las personas para mantener y actualizar información en el contexto del MI (Oberauer \& Kliegl, 2006).

En las siguientes secciones se describe el paradigma empleado en este estudio, se presenta el marco general de modelación y la formalización del MI.

\section{La tarea de actualización de memoria de trabajo}

La tarea de actualización de memoria de trabajo es una variante desarrollada a partir del trabajo de Oberauer y Kliegl (2006). Este experimento incluye dos condiciones experimentales: la condición control y la condición de inhibición.

Un ensayo en la condición control inicia con la presentación de uno, dos o tres estímulos distribuidos en una matriz de tres por cuatro. Primero, los participantes codifican la posición inicial de cada estímulo. Seguido a la fase de codificación, una flecha negra junto con la imagen de uno de los estímulos presentados anteriormente señala el primer paso de actualización. Un paso de actualización involucra que el o la participante cambie mentalmente el estímulo moviéndolo una celda desde la posición actual y en la dirección señalada por la flecha negra. Los participantes son instruidos para que recuerden la nueva localización del estímulo. La tarea involucra cinco o seis pasos de actualización y seguidamente la posición final de cada estímulo es requerida. Los participantes responden por medio de un clic con el mouse de la computadora en la casilla que ellos consideran debería estar un estímulo en particular. Para cada paso de actualización se proporciona una cantidad de tiempo limitada. Este tiempo es fijo entre pasos de actualización pero varía entre ensayos, con el objetivo de estimar funciones de tiempo-precisión. Estas funciones permiten estimar la cantidad de tiempo promedio que los participantes necesitan para alcanzar su rendimiento máximo.

En la condición de inhibición aparecen en orden aleatorio flechas negras y flechas blancas (ver Figura 1). De igual manera que en la condición control las flechas negras indican mover mentalmente el estímulo en la dirección señalada por la flecha mientras que las flechas blancas indican mover mentalmente el estímulo una casilla pero en la dirección opuesta a la indicada. Por lo tanto, los participantes en la condición inhibición tenían que desplazar su atención entre las dos tareas indicadas por el color de las flechas, y se espera que ante la presentación de las flechas blancas los participantes inhiban la tendencia natural a mover los estímulos en la dirección indicada por la flecha y que los muevan en la dirección opuesta.

\section{El modelo de interferencia (MI, Oberawer \& Kliegl, 2006)}

La figura 2 muestra una representación esquemática del MI presentada en tres paneles. El panel superior de esa figura ilustra el MI como una red de cuatro capas - de arriba hacia abajo: la capa de resultados, la capa de foco atencional, las de unidades características, y la capa de contexto. Por simplicidad el panel central e inferior de esta misma figura omite la capa de resultados. El panel superior bosqueja un estado en el 


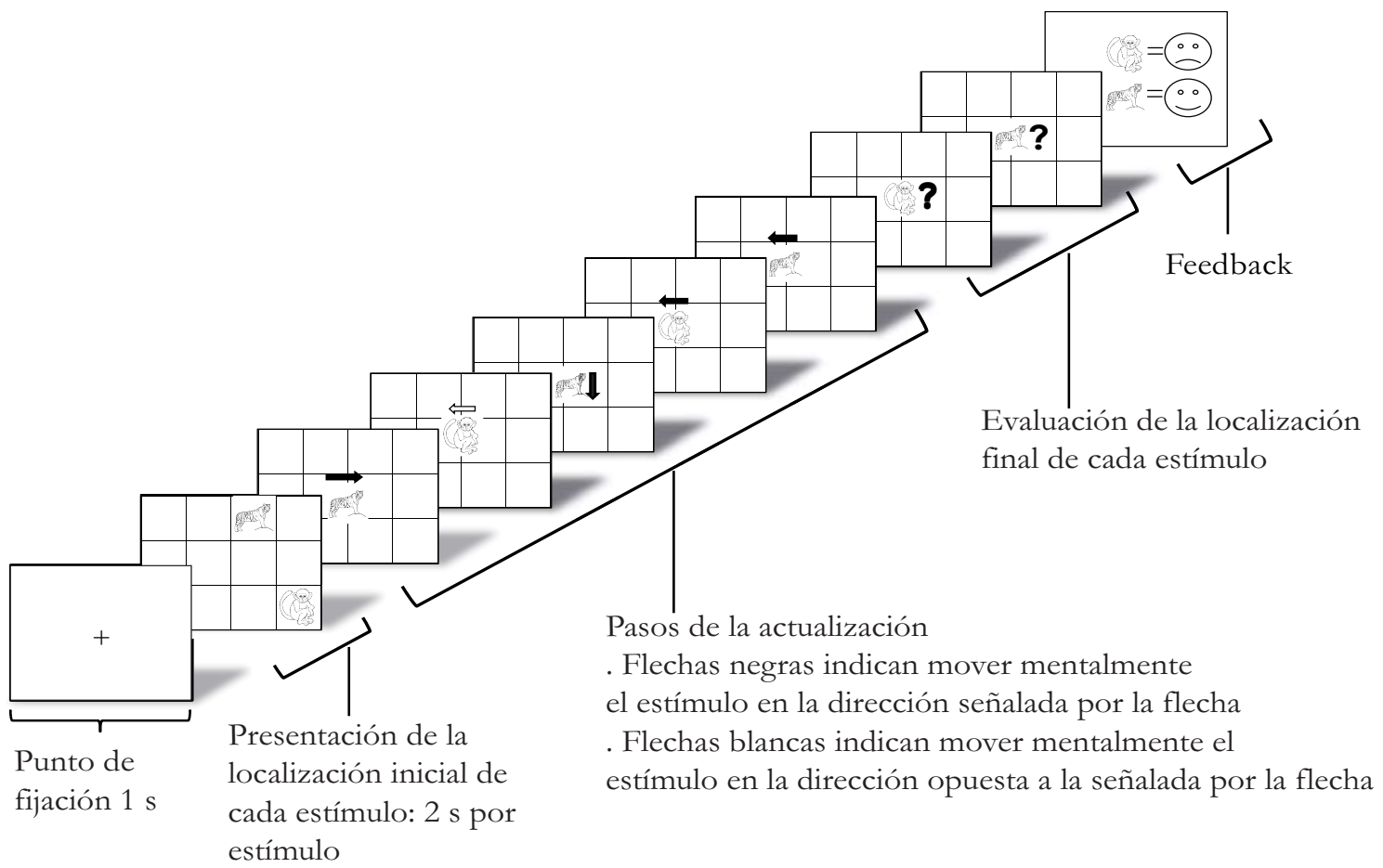

Figura 1. Ejemplo de un ensayo de la condición inhibición de la tarea de actualización de memoria de trabajo.

cual la representación de dos estímulos es mantenida en memoria de trabajo (i.e., tigre y mono). En esta sección se utilizará el término "imagen" para referirnos a la representación mental del estímulo. El estímulo, la imagen a ser actualizada (i.e., la representación objetivo), es ilustrada en un recuadro al lado izquierdo. Al lado derecho se muestra otra imagen en memoria de trabajo denominada, en este modelo, representación competidora. Las representaciones en memoria de trabajo son simbolizadas como un set de unidades activadas en la capa de características.

Un presupuesto del MI es que las representaciones en memoria de trabajo comparten una proporción de unidades características con una o varias de las otras representaciones. Las imágenes a ser recuperadas son representadas en la capa de características y las claves contextuales que pueden ser usadas para recuperarlas son simbolizadas en la capa de contexto. Por ejemplo, en la tarea de actualización los participantes deben recuperar mentalmente la localización en la que se encuentra la imagen. En la tarea, el estímulo funciona como clave contextual para recuperar su localización en la matriz de 3 x 4 casillas (ver figura 1). Por lo tanto, su localización se ilustra en la capa de características y el estímulo es representado en la capa de contexto. Las características del estímulo son ligadas a las características de su localización espacial, esto es, alguna de las 12 casillas de la matriz de 3 x 4 (ver figura 1). El modelo asume que disparos sincronizados de neuronas pueden ser el mecanismo que liga las características de una representación con su localización espacial. En el ejemplo de la figura 2, la sincronización es ilustrada mediante unidades de contexto, características, foco atencional, y resultados del mismo color. Dos imágenes son almacenadas: la imagen objetivo que es la imagen que tiene que ser recuperada y que es asociada con unidades características azules, y la imagen competidora, la cual es representada por unidades características grises (i.e., la imagen del mono). 


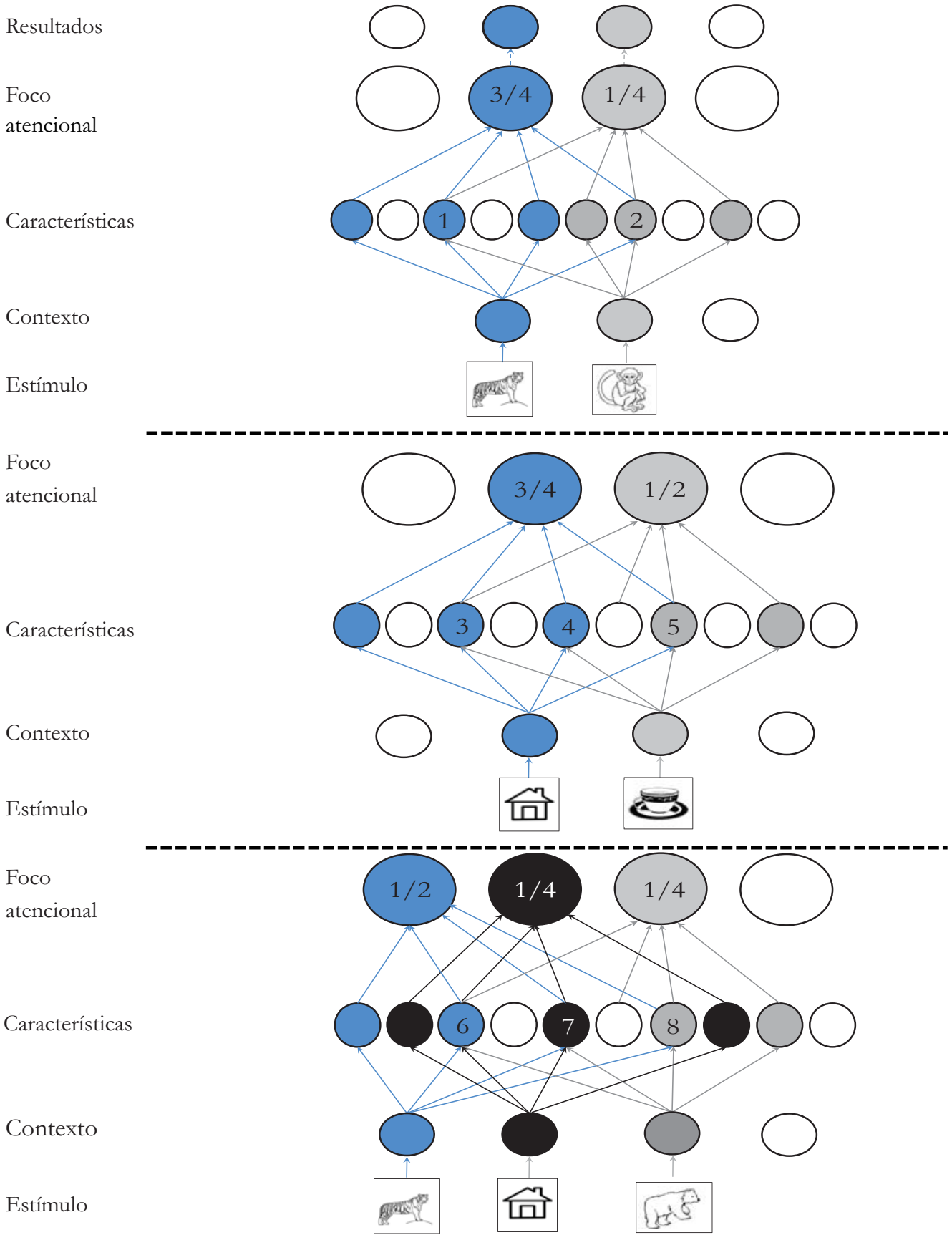

Figura 2. Representación esquemática del MI.

Actualidades en Psicología, 29(119), 2015, 43-62 
El MI asume que cualquier representación en memoria de trabajo comparte una proporción de sus características (i.e., traslape de características) y a mayor similitud entre representaciones se comparten más de ellas. En el ejemplo, las imágenes comparten dos unidades características denotadas con los números 1 y 2 . Si una unidad característica se dispara en sincronía en la fase de disparo de una imagen, dicha unidad, no se dispara en sincronía con la fase de la otra imagen. Consecuentemente, la otra imagen pierde esa unidad característica. Este mecanismo se denomina interferencia por sobre escritura de características (Nairne, 1990). La figura muestra que cada imagen pierde una característica debido a sobre escritura. La imagen objetivo pierde la unidad característica 2 y la imagen competidora pierde la unidad característica 1. Cuando una cantidad $n$ de representaciones mentales son mantenidas simultáneamente en memoria de trabajo cada representación sufre interferencia por parte de otras representaciones.

Con el fin de recuperar la imagen para ser actualizada es necesario transferir la suma de la activación de las unidades características a la representación de la imagen en la capa del foco atencional (Oberauer \& Kliegl, 2006). En el ejemplo, todas las unidades características que se disparan en sincronía con la fase azul, la cuál es la fase de la imagen objetivo, transfiere su activación a la capa del foco atencional. Por lo tanto, la proporción de características que no han sido sobre escritas para una imagen en particular se traduce directamente en el nivel de activación asintótico de la imagen objetivo en la capa del foco atencional. En la Figura 2, la imagen objetivo transfiere solo $3 / 4$ de su activación máxima posible debido a que perdió la unidad característica denotada con el número 2. Además, la unidad característica 1 , en la cual las imágenes se sobre escriben, también transfiere su activación a la unidad del foco atencional de la imagen competidora. Esto último refleja la existencia de una activación ruidosa en la capa del foco atencional. Los niveles de activación de la imagen objetivo y la imagen competidora deben ser interpretados como valores esperados de una variable aleatoria. Así, las imágenes pueden ser recuperadas erróneamente debido al ruido en la capa del foco atencional. El MI incluye el parámetro $\sigma$, el cual se puede asumir que captura interferencia por confusión entre todas las representaciones en memoria de trabajo. En el ejemplo, la activación relativa de la imagen objetivo (i.e., 3/4) y la competidora (i.e., 1/4) podría permitir la selección correcta de las características de la imagen objetivo y consecuentemente la imagen podría ser actualizada. Entonces su activación se propaga a la capa de resultados y una nueva secuencia de pasos de actualización inicia. El tiempo promedio requerido para recuperar y actualizar una imagen se refleja en el parámetro $r$.

Actualizar una imagen del paso de actualización inmediatamente anterior es más rápido que actualizar una imagen que no lo ha sido en el paso previo. Esto se debe a que la imagen está fuertemente activada en la capa del foco atencional; y por lo tanto, no es necesario propagar su activación de la capa de unidades características a la capa del foco atencional. Este presupuesto se basa en el denominado costo por cambio de objeto (Garavan, 1998; Oberauer, 2003). Para dar cuenta de este costo el MI distingue entre dos parámetros de velocidad de procesamiento: $r_{1}$ y $r_{D M>1}$. El parámetro $r_{1}$ refleja la velocidad de actualización cuando hay únicamente 1 representación en memoria de trabajo, esto es, cuando el foco atencional no tiene que desplazarse entre representaciones en memoria de trabajo. El parámetro $r_{D M>1}$ refleja la velocidad de procesamiento cuando hay más de una representación en memoria de trabajo, situación en la que es necesario el desplazamiento del foco atencional entre las representaciones en memoria de trabajo. El subíndice $D M$ es la abreviatura de demanda de memoria, la cual especifica el número de representaciones mantenidas en memoria de trabajo.

La presente versión del MI incluye el parámetro $r_{D M>2}$ para la situación en la que hay más de dos representaciones en memoria de trabajo. El motivo para incluir este parámetro es que un incremento en el número representaciones promueve la competencia por ser actividades en el foco atencional, y con ello, incrementando el tiempo del proceso de selección de la representación objetivo. Así, la fuerte competición 
entre representaciones en memoria de trabajo podría disminuir la velocidad de recuperación de cualquier otra representación debido inhibición lateral (Usher \& McClelland, 2001). Con base en este mecanismo, se puede asumir que cada representación inhibe la activación de las otras, y que la representación con un mayor grado de activación es la que ejerce un mayor grado inhibición. Esto último es lo que facilita la selección de la representación con un mayor nivel de activación.

El MI acomoda dos hallazgos bien documentados: el efecto de la similitud fonológica (Conrad \& Hull, 1964; Copeland \& Radvansky, 2001; Lobley, Baddeley, \& Gathercole, 2005) y la capacidad máxima promedio de almacenar representaciones independientes en memoria de trabajo (Cowan, 2001). El efecto de la similitud fonológica ha sido documentado por estudios que demuestran que palabras que son fonológicamente similares son más difíciles de mantener en memoria (Conrad \& Hull, 1964; Copeland \& Radvansky, 2001; Lobley, Baddeley, \& Gathercole, 2005).

El panel central de la Figura 2 ilustra este fenómeno. Este panel esquematiza una situación en la que dos imágenes son almacenadas: La imagen objetivo "casa" y la imagen competidora "taza". Debido a que la representación fonológica de estas imágenes es similar muchas de sus características se traslapan. En el ejemplo, la imagen objetivo, denotada en azul, pierde la unidad característica 5 y la competidora pierde las características 3 y 4 . Consecuentemente, la activación de la imagen objetivo es $3 / 4$. En el caso de la imagen competidora esta puede propagar un $1 / 2$ de su activación a su unidad en la capa del foco atencional y el otro medio a la unidad de la imagen objetivo. Esto, a su vez, incrementa la probabilidad de seleccionar la imagen errónea en la capa del foco atencional (i.e., interferencia por confusión). Por lo tanto, en el marco del MI, el efecto de la similitud fonológica es producto de interferencia por sobre escritura e interferencia por confusión.

El panel inferior de la Figura 2 bosqueja un estado en el cual tres imágenes son mantenidas en memoria de trabajo. Dado el presupuesto de que cualquier representación en memoria de trabajo comparte una proporción de sus unidades características con las demás, un incremento en la cantidad de representaciones facilita el traslape, y con ello, la sobre escritura entre representaciones. En el ejemplo, la representación objetivo "tigre" pierde las unidades características 7 y 8; y por lo tanto, ésta sólo propaga un $1 / 2$ de su activación máxima. La representación competidora "casa" pierde la unidad característica 6, la otra representación competidora "oso" pierde las unidades características 6 y 7. De ahí que la activación asintótica máxima de la representación objetivo en la capa del foco atencional sería un $1 / 2$ y la activación asintótica de las representaciones competidoras será un 1/4. En este escenario, debido a ruido, las representaciones objetivo co-activadas podrían alcanzar su activación máxima debido a que su nivel de activación es similar con respecto a la imagen objetivo. De esta manera, el panel inferior de la figura 2 indica que la selección correcta de una representación depende de la pérdida de características debido a sobre escritura y a ruido en la capa del foco atencional.

Para resumir, el MI tiene cinco parámetros básicos. El parámetro $C$ que refleja interferencia por sobre escritura, el parámetro $\sigma$ que modela interferencia por confusión y los parámetros que reflejan la velocidad de procesamiento en demandas de memoria iguales a 1 (i.e., $r_{1}$ ), demandas de memoria mayor que 1 (i.e., $r_{D M>1}$ ) y demandas de memoria mayores que 2 (i.e., $r_{D M>2}$ ).

Las predicciones del MI pueden ser graficadas como funciones de tiempo-precisión, el cuál es un procedimiento que ayuda a estimar el tiempo requerido por los participantes para alcanzar el nivel asintótico de recuperación de representaciones en memoria de trabajo. La Figura 3 esboza el efecto de cambiar el valor de algunos parámetros del MI en funciones de tiempo-precisión.

El panel A de la Figura 3 -denotado como Línea base- simula las predicciones del MI en la tarea de actualización de memoria de trabajo. El eje y representa la proporción de respuestas correctas como función del tiempo disponible para actualizar las representaciones - eje $x$. Las líneas negras, las discontinuas y las 


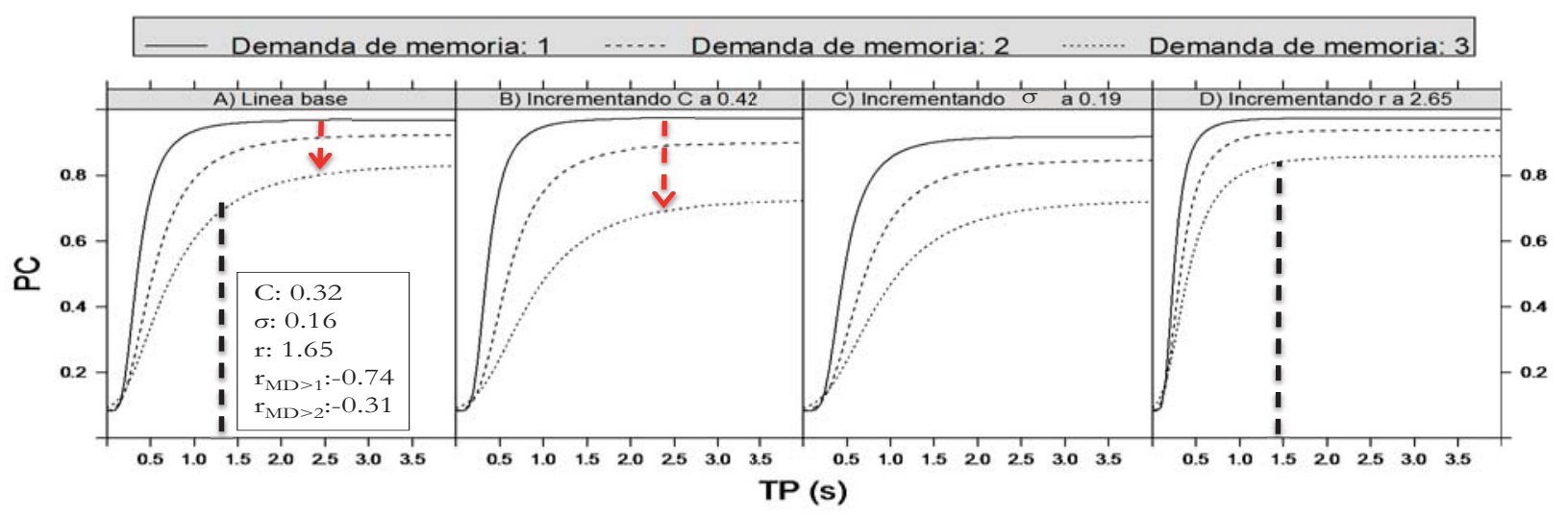

Figura 3. Representación de los parámetros del MI en funciones de tiempo-precisión. PC = proporción de respuestas correctas; TP (s) = tiempo de presentación en segundos.

punteadas representan la proporción de respuestas correctas para demandas de memoria de uno, dos y tres objetos, respectivamente. El recuadro dentro del panel línea base resume los valores de los parámetros estimados por el MI: interferencia por sobre escritura $-\mathrm{C}$, interferencia por confusión $-\sigma-\mathrm{y}$ los parámetros de velocidad de procesamiento, $r_{1}, r_{D M>1}$, and $r_{D M>2}$. La línea roja representa la cantidad de interferencia por sobre escritura $-C=0.32$ - desde una representación a tres representaciones.

El panel B esboza el efecto de incrementar, únicamente, el parámetro $C$ de 0.32 a 0.42 , lo cual resulta en una reducción de la proporción de respuestas correctas predichas para demandas de memoria mayores que uno. De igual manera, la flecha roja muestra la interferencia por sobre escritura de una representación a tres representaciones en memoria de trabajo.

El tercer panel - de izquierda a derecha exhibe el efecto de incrementar el parámetro $\sigma$ de 0.16 a 0.19 mientras se mantienen constantes los valores de los parámetros del modelo de línea base. Esto muestra que independientemente de la demanda de memoria un incremento en este parámetro está relacionado con una reducción del desempeño.

El panel D indica que relativo a los valores especificados en el panel línea base un incremento de 1.65 a 2.65 en el parámetro $r$ se traduce en una menor cantidad de tiempo para alcanzar la proporción máxima de promedio de respuestas correctas. La línea vertical discontinua en el panel derecho (i.e., panel D) muestra que la proporción asintótica de respuestas correctas con tres representaciones en memoria de trabajo es alcanzada aproximadamente a los $1500 \mathrm{~ms}$, mientras que la línea vertical discontinua en el panel línea base indica que a los $1500 \mathrm{~ms}$ no se ha alcanzado la proporción asintótica de respuestas correctas.

\section{Implementación formal de MI}

De acuerdo con el MI los límites de la capacidad de memoria de trabajo nacen debido a la disponibilidad de las representaciones al momento de su recuperación, lo cual depende de su nivel de activación. Formalmente, el nivel de activación de la representación objetivo es denotado como $A_{i(M I)}$ y el nivel de las representaciones competidoras se denota $A_{j(M I)}$. En donde el subíndice $i$ indica la activación de la representación objetivo $i$, el subíndice $j$ indica 
el nivel de activación de las representaciones competidoras y $M I$ indica una versión particular del MI. De acuerdo con el MI $A_{i(M I)}$ es dado por la siguiente ecuación:

$$
A_{i(M I)}=(1-C / 2)^{n-1},
$$

en donde $C$ es un parámetro libre reflejando interferencia por sobre escritura, $n$ es el número de representaciones en memoria de trabajo. En la capa del foco atencional, la activación asintótica de la representación objetivo $i$ al tiempo $t, a_{i(M I I}(t)$, sigue una función negativamente acelerada como la descrita por McClelland (1979):

$$
a_{i(M I)}(t)=A_{i(M I)}(1-\exp (t r)),
$$

donde $t$ es el tiempo desde el inicio del proceso de recuperación y $r$ la tasa de activación. Acá $r$ es un parámetro libre que refleja la tasa de activación de la representación objetivo en la capa del foco atencional, no obstante, este parámetro estimado a partir de todas las ecuaciones del modelo refleja el tiempo promedio para actualizar y recuperar las representaciones (Oberauer \& Kliegl, 2006). Así, este parámetro como variable latente estima la velocidad de procesamiento en memoria de trabajo.

En general, la activación de las representaciones competidoras (i.e., $\left.a_{j}(t)\right)$ para demandas de memoria mayores que uno es:

$$
a_{j}(t)=(C / 2)(1-C / 2)^{n-2}(1-\exp (-t r)),
$$

donde cada representación competidora toma $C / 2$ de las $C$ unidades características que esta comparte con la representación objetivo, por lo tanto, esto refleja la proporción de unidades características que la representación objetivo comparte con cualquier representación competidora y que se mantienen unidas a ella. Entonces, la probabilidad de que entre una cantidad $n$ de representaciones en memoria de trabajo la representación objetivo propague su activación a la capa del foco atencional depende, también, del ruido en el sistema. Por lo tanto, la probabilidad de recuperar una representación puede ser descrita como la ecuación de Boltzmann (Anderson \& Lebiere, 1998, p. 90):

$$
p_{i}=\frac{\exp \left(a_{i}(\mathrm{t}) / T\right)}{\sum_{j=1}^{n} \exp \left(a_{j}(\mathrm{t}) / T\right)},
$$

$p i$, es la probabilidad de transferir la activación de la representación objetivo $i$, al tiempo $t$ (i.e., ai $(t))$ a la capa de foco atencional dada la activación de las representaciones restantes al tiempo $t$ (i.e., aj(t)), y el ruido en el sistema. El parámetro $T$ captura el ruido en el sistema el cual es especificado como la desviación estándar de la activación dado por $T=\operatorname{sqrt}(6) * \sigma / \pi$, donde $\sigma$ es un parámetro libre reflejando el ruido de la activación. Con el fin de caracterizar con mayor detalle el proceso de recuperación la ecuación 4 puede ser expandida a

$p_{i}=\frac{\exp \left(a_{i}(\mathrm{t}) / T\right)}{\exp \left(a_{i}(\mathrm{t}) / T\right)+(n-1) \exp \left(a_{j}(\mathrm{t}) / T\right)+(12-n) \exp (0 / T)}(4)$

Esta expansión toma en cuenta que las casillas actualmente no asociadas con una representación pueden ser recuperadas erróneamente debido al ruido (para detalles ver Oberauer \& Kleigl, 2006). Todas las casillas que no están asociadas con una representación se asume que tienen una activación con un valor de cero. Por la tanto, en la matriz de $3 \times 4$ el número de casillas no ocupadas es 12-n (ver Figura 1). Los demás términos del denominador reflejan la activación de la representación objetivo, $a_{i}$, la activación de los $a_{j}$ y la activación de los n-1 competidores, .

Al final del ensayo, después de la secuencia de pasos de actualización, los participantes necesitan recuperar la posición final de cada estímulo. La probabilidad de recuperar la localización final de cada estímulo es el producto de la probabilidad de recuperar la localización de cada estímulo en cada paso de actualización $m$.

El MI modela respuestas correctas en condiciones de olvido completo. En tal caso, los participantes deben seleccionar una de las 12 casillas de manera 
aleatoria. La probabilidad de adivinar la localización correcta es $1 / 12$. Por lo tanto, la precisión de recuperar exitosamente cada localización al final del ensayo es calculada como

$$
P_{i}=1 / 12+(1-1 / 12) p_{i}^{m \prime \prime} p_{i}^{\prime}
$$

En esta ecuación, $P i$ es la probabilidad de recuperar la localización correcta de cada estímulo $i$, al final del ensayo, $m$ expresa el número promedio de pasos de actualización en cada estímulo $i$, pi es la probabilidad de realizar exitosamente un paso de actualización y $p^{\prime}{ }_{i}$ representa la probabilidad de éxito al final del ensayo, la cual es calculada de la misma manera que pi pero con tiempo $t$ indefinido. Lo anterior se debe a que no hay tiempo límite para la recuperación de la posición final.

En este trabajo, se examinó el papel de la inhibición y el desplazamiento de la atención en la memoria de trabajo evaluando dos versiones del MI.

La primer versión, denotada MI, incluyó el intercepto del parámetro $C$ (1.e., $C_{I n t}$ ), el intercepto del parámetro $\sigma$ (i.e., $\sigma_{I n t}$ ), el intercepto del parámetro $r$ (i.e., $\left.r_{\text {Int }}\right)$, las diferencias en el parámetro $r$ para demandas de memoria mayores que uno (i.e., $\left.r_{D M>1}\right)$ y las diferencias en el parámetro $r$ para demandas de memoria mayores que dos (i.e., $\left.r_{D M>2}\right)$.

La segunda versión, denotada MIr, evaluó la hipótesis de que la inclusión de flechas negras y blancas en la condición de inhibición disminuye la velocidad de actualización de las representaciones debido al desplazamiento de la atención entre la tarea denotada por las flechas negras y blancas, y debido a que los participantes se les solicita privarse de la tendencia natural de recodificar la localización de un estímulo en la dirección señalada por las flechas blancas. Por lo tanto, es razonable asumir que el desplazamiento de la atención entre tareas y la inhibición de una respuesta natural consumen tiempo, lo cual debería verse reflejado en mayores estimados del parámetro $r$ de la condición inhibición en comparación con la condición control. Para buscar evidencia en favor de MIr se incluyeron velocidades de procesamiento distintas para cada condición experimental y cada demanda de memoria. De esta manera el MIr estimó los siguientes parámetros: el intercepto del parámetro $C$ (i.e., $C_{I n t}$ ), el intercepto del parámetro $\sigma$ (i.e., $\sigma_{I n t}$ ), el intercepto del parámetro $r$ (i.e., $r_{I n t}$ ), las diferencias en el parámetro $r$ para cada condición experimental (i.e., $r_{\text {Inbi-Contr. }}$ ), las diferencias en el parámetro $r$ para demandas de memoria mayores que uno (i.e., $r_{\text {Contr:DM>1 }}$ ) y demandas de memoria mayores que dos (i.e., $r_{\text {Cont:DM>2 }}$ ) en la condición control, y las diferencias en el parámetro $r$ para demandas de memoria mayores que uno (i.e., $r_{\text {InhkDMM1}}$ ) y demandas de memoria mayores que dos (i.e., $r_{I n h i . D M>2}$ ) en la condición inhibición.

\section{Método}

\section{Participantes}

Un total de 20 estudiantes de la Universidad de Costa Rica realizaron el experimento (14 mujeres, M $=20.75$ años, rango de edad: 20-25 años) los cuales no recibieron pago alguno por su participación. Cada participante completó un consentimiento informado aprobado por el Comité Ético Científico de la Universidad de Costa Rica.

\section{Instrumentos y diseño}

La tarea fue programada en E-prime 2.0 (Schneider, Eschman, \& Zuccolotto, 2002). Fueron utilizadas 9 imágenes monocromáticas representando objetos o animales (ver Figura 1 para un ejemplo de dos de estas imágenes). La selección de los estímulos permitió que los nombres de las imágenes fueran de similar longitud con una desigualdad fonológica máxima para minimizar los efectos de la representación verbal de cada imagen. La etiqueta de cada una de las palabras fueron: "trigo", "pan", "cama", "moto", "tigre", "sol”, "casa", "mono" y "pez".

El experimento cruzó tres factores dentro de los sujetos: condición experimental (i.e., condición control vs. condición inhibición), demanda de memoria de uno, dos y tres estímulos, y tiempo de presentación. El experimento incluyó tres sesiones de una hora, los participantes realizaron una sesión por día. En una sesión ellos realizaron 12 bloques de ensayos: dos bloques por cada demanda de memoria y cada 
condición experimental. El orden de presentación de las condiciones experimentales y de cada demanda de memoria fue contrabalanceado entre todos los participantes. En total, los participantes completaron 216 ensayos por condición experimental.

Cada bloque incluyó doce ensayos con diferentes tiempos de presentación para los pasos de actualización. Los doce tiempos de presentación fueron desde $563 \mathrm{~ms}$ hasta $3474 \mathrm{~ms}$ con un incremento constante del 18\% entre tiempos de presentación sucesivos. Los tiempos de presentación de cada bloque fueron categorizados en rápidos, medios y lentos con cuatro tiempos de presentación en cada categoría. El orden de presentación de las categorías fue fijado dentro de cada bloque repitiendo la secuencia mediano - lento - rápido. Dentro de cada categoría, los tiempos de presentación fueron escogidos aleatoriamente y sin remplazo.

\section{Procedimiento}

En la condición control al principio de cada ensayo se desplegó en la pantalla de la computadora la demanda de memoria y el nombre de los estímulos que tenían que ser actualizados dentro de la matriz de $3 \mathrm{x}$ 4 casillas. El ensayo inició con un punto de fijación de $1000 \mathrm{~ms}$ en el centro de la pantalla. Este fue seguido por la presentación de uno, dos o tres estímulos ubicados en alguna de las casillas de la matriz. Los participantes tenían que codificar sus localizaciones durante la fase de codificación la cual duró $2 \mathrm{~s}$ por estímulo. Por ejemplo, el tiempo de la fase de codificación para un ensayo con demanda de memoria de tres estímulos fue de $6 \mathrm{~s}$. Un paso de actualización fue indicado por la presentación simultánea de una flecha negra señalando una de ocho posibles direcciones (e.g., arriba, abajo, izquierda, derecha o diagonal) y la imagen de uno de los estímulos a codificar. Los participantes fueron instruidos para cambiar mentalmente la localización del estímulo una casilla desde la posición actual y de acuerdo con la dirección indicada por la flecha. Posteriormente, los participantes debían recordar la nueva localización de la imagen. Cada ensayo consistió de cinco o seis pasos de actualización y todos los estímulos fueron actualizados al menos una vez. Después de los pasos de actualización, los participantes tenían que proporcionar la posición final de cada estímulo por medio de un clic con el mouse de la computadora en la casilla específica de la matriz. Posteriormente de que todas las respuestas fueron proveídas la presentación del respectivo estímulo junto con una "carita feliz" o una "carita triste" indicó si las respuestas eran correctas o incorrectas, respectivamente. La condición inhibición fue idéntica a la condición control con la excepción de que flechas blancas o negras fueron presentadas en los pasos de actualización. Cuando se presentaron flechas blancas los participantes fueron instruidos para que cambiaran mentalmente la posición del estímulo en dirección opuesta a la señalada por la flecha. Un ensayo podía tener una, dos o tres flechas blancas.

\section{Análisis estadístico}

Los modelos fueron implementados como nonlinear mixed-effects models (NLMMs). Cada modelo predice la proporción de respuestas correctas como una función de las variables independientes tiempo de presentación (12 niveles determinando el parámetro t), demanda de memoria (3 niveles determinando el parámetro n) y las condiciones experimentales (condición control y condición inhibición reflejando diferentes parámetros en cada modelo).

En el contexto de NLMMs, los efectos fijos especifican la influencia de las variables independientes en los parámetros del modelo. Estos efectos son estimados como las diferencias en la variable dependiente (i.e., la proporción de respuestas correctas) relativo a los niveles de las condiciones experimentales y los interceptos. Para el parámetro $r$ se codificaron los efectos fijos para las condiciones experimentales control, inhibición y demandas de memoria como contrastes de diferencias sucesivas (Venables y Ripley, 2002, p. 148).

Estos contrastes estiman el intercepto (i.e., la gran media) y capturaron las diferencias entre las medias de niveles sucesivos (e.g., demanda de memoria 2 - demanda de memoria 1, demanda de memoria 3 - demanda de memoria 2). Así, el efecto fijo de las condiciones experimentales estima la diferencia entre 
la media de la condición inhibición menos la media de la condición control y la gran media. Además, en el contexto de los NLMMs diferencias individuales en el intercepto o en las diferencias pueden ser estimadas como efectos aleatorios (i.e., componentes de la varianza). Si un componente de la varianza mejora el valor de los índices de ajuste esto puede ser interpretado como diferencias entre participantes asociadas a los efectos fijos.

Los parámetros del modelo fueron estimados como sigue. Primero se promediaron la proporción de respuestas correctas por participante, demanda de memoria, condiciones experimentales y tiempos de presentación. Segundo, esta información fue usada para estimar los parámetros del modelo separadamente por cada participante. Siguiendo las fórmulas de cada modelo los modelos estimaron un set de parámetros para cada participante. Tercero, los coeficientes estimados fueron usados como valores iniciales para estimar los efectos fijos y los componentes de la varianza de los NLMMs.

La estrategia para la construcción de modelos fue teóricamente motivada. Por lo tanto, se incluyeron los efectos fijos especificados para MI y MIr (para detalles de los parámetros de cada modelo ver la sección anterior). Con respecto a la inclusión de los componentes de la varianza los modelos incluyeron el máximo número de interceptos que mejoraron el ajuste de cada modelo.

Para la selección de modelos se usaron múltiples criterios: el logaritmo de la verosimilitud proporcionado por la función nlme en $\mathrm{R}$, el criterio de información Akaike (AIC) y el Criterio de información bayesiana (BIC). También se calculó el $\mathrm{R}_{a d j}^{2}$ (McElree y Dosher, 1989) como índice descriptivo de la proporción de la varianza explicada por el modelo. El AIC y el BIC permiten la comparación entre modelos de diferente complejidad y son derivados del logaritmo de la verosimilitud. El modelo con los menores valores de AIC y BIC es el preferido. Para desambiguar el proceso de selección de modelos se incluyeron las diferencias del AIC y BIC (i.e., $\triangle$ AIC, $\triangle \mathrm{BIC}$, respectivamente). Los $\triangle$ AIC y $\triangle$ BIC se calculan siguiendo el mismo procedimiento. Primero, se elige de manera tentativa un modelo ganador, esto es, el modelo que muestra los AIC o BIC con menores valores. Luego el ganador

Tabla 1

Modelos y sus indices de ajuste

\begin{tabular}{|c|c|c|c|c|c|c|c|c|c|}
\hline Modelo & Efectos fijos & $\begin{array}{l}\text { Efectos } \\
\text { aleatorios }\end{array}$ & G1 & AIC & $\Delta \mathrm{AIC}$ & $\mathrm{BIC}$ & $\Delta \mathrm{BIC}$ & Log-Lik & $\mathrm{R}_{a \mathrm{~d} j}^{2}$ \\
\hline MI & $\begin{array}{l}C_{\text {Int. }}, \sigma_{\text {Int. }}, r_{\text {Int. }}, \\
\mathrm{r}_{D M>1}, \mathrm{r}_{D M>1}\end{array}$ & $C_{\text {Int. }}, \sigma_{\text {Int. Int. }} r_{r}$ & 9 & -1402.486 & 403.753 & -1355.035 & 387.936 & 710.243 & 0.78 \\
\hline MIr & $\begin{array}{l}C_{\text {Int. }}, \sigma_{\text {Int. }}, r_{\text {Int. }}, \\
r_{\text {Inhi.-Contr. }}, \\
r_{\text {Contr.DM }>1}, \\
r_{\text {Contr:DM }>2}, \\
r_{\text {Inhi.DM }>1}, r_{\text {Inhi.DM }>2}\end{array}$ & $C_{\text {Int. }}, \sigma_{\text {Int. }}, r_{\text {Int. }}$, & 12 & -1806.240 & 0 & -1742.971 & 0 & 915.119 & 0.78 \\
\hline
\end{tabular}

Nota. Gl = Grados de libertad (i.e., número de parámetros estimados más la varianza residual); AIC = Criterio de Información de Akaike; BIC = Criterio de Información Bayesiano; $\triangle \mathrm{AIC}=$ Diferencias entre el modelo con el AIC más bajo y los modelos restantes; $\triangle \mathrm{BIC}=$ Diferencias entre el modelo con el BIC más bajo y los modelos restantes; Log-lik = logaritmo de la verosimilitud; Inhi. $=$ condición inhibición; Contr. $=$ condición control; Int. = intercepto $($ gran media $) ; \mathrm{DM}=$ demanda de memoria. 
preliminar adopta un valor de 0 y los modelos restantes adoptan las diferencias. De acuerdo con Burnham y Anderson (2002, p.70), valores $\triangle$ AIC entre 0 y 2 indican poca evidencia para discriminar entre modelos, valores de 4 a 7 sugieren poco apoyo para el modelo con valores AIC más altos y diferencias mayores que 10 indican que no hay evidencia a favor del modelo con los mayores valores en el AIC. Los $\triangle \mathrm{BIC}$ pueden ser interpretados de la misma manera (Wasserman, 2000).

\section{Resultados}

La tabla 1 resume los parámetros incluidos en cada modelo y sus índices de ajuste. La tabla muestra que, de acuerdo con los criterios de selección, el MIr, es el modelo que muestra los mejores índices de ajuste. Lo anterior es claro en los índices $\triangle$ AIC y $\triangle \mathrm{BIC}$ pues los valores del MI superan las 10 unidades, indicando que no hay evidencia a favor de este modelo. Esto sugiere que la inclusión de los parámetros $r_{\text {Inhi.Contr. }}, r_{\text {Inhi.DM }>1}$ y $r_{\text {Inbi.DM }>2}$ explica parte adicional de la variabilidad de los datos. Después de corroborar que el MIr cumple con los presupuestos para los NLMMs fue definido como el modelo que mejor ajusta los datos.
La tabla 2 resume los parámetros del MIr. De acuerdo con lo esperado los estimados negativos de los parámetros $r_{\text {Inhi-Contra }}, r_{\text {Inhi.DM }>1}, \mathrm{y} r_{\text {Inhi.DM }>2}$ muestran que los estimados de la condición control comparados con los estimados de la condición inhibición son mayores. Este hallazgo sugiere que los participantes empleaban una mayor proporción de tiempo actualizando las representaciones en esta última condición.

La figura 4 muestra los datos junto con las predicciones derivadas de los parámetros del MI panel superior - y del MIr - panel inferior. Como sugiere la figura el MIr es quien mejor captura el patrón arrojado por los datos. Este modelo incluye los interceptos para los parámetros $C, \sigma$ y $r$ y las diferencias entre condiciones experimentales, y demandas de memoria de parámetro $r$. En este modelo todos los parámetros demostraron predecir en buena forma la proporción de respuestas correctas de los participantes en la tarea de actualización. De esta manera, los hallazgos de este experimento brindan evidencia adicional para los principales supuestos del MIr el cual asume que el parámetro $C$ refleja susceptibilidad a la interferencia por sobre-escritura, la cual surge por la pérdida de asociaciones entre las unidades características de una representación y una

Tabla 2

Parámetros estimados del modelo MIr

\begin{tabular}{|c|c|c|c|c|c|}
\hline \multicolumn{6}{|c|}{ MIr } \\
\hline Efecto & Parámetro & Valor & IC $95 \%$ & $\begin{array}{l}\text { Error } \\
\text { estándar }\end{array}$ & $T$ (valor- $p$ ) \\
\hline Intercepto & $C_{I n t .}$ & .318 & {$[.268, .369]$} & 0.025 & $12.295(<.001)$ \\
\hline Intercepto & $\sigma_{I n t}$ & .167 & {$[.155,0.180]$} & 0.006 & $25.526(<.001)$ \\
\hline Intercepto & $r_{\text {Int. }}$ & 1.427 & {$[1.278,1.576]$} & 0.076 & $18.680(<.001)$ \\
\hline Diferencias & $r_{\text {Inbi.Contr. }}$ & -.636 & {$[-.740,-.532]$} & 0.053 & $-11.972(<.001)$ \\
\hline Diferencias & $r_{\text {Contr:DM>1 }}$ & -.849 & {$[-1.148,-.550]$} & 0.152 & $-5.559(<.001)$ \\
\hline Diferencias & $r_{\text {Contr:DM>2 }}$ & -.338 & {$[-.469,-.207]$} & 0.066 & $-5.047(<.001)$ \\
\hline Diferencias & $r_{\text {Inbi.DM }>1}$ & -.273 & {$[-.364,-.182]$} & 0.046 & $-5.881(<.001)$ \\
\hline Diferencias & $r_{\text {Inbi.DM }>2}$ & -.116 & {$[-.195,-.037]$} & 0.040 & $-2.873(<.01)$ \\
\hline
\end{tabular}

Nota. Gl = Grados de libertad; Contr. = condición control; Int. = intercepto (gran media); DM = demanda de memoria. 

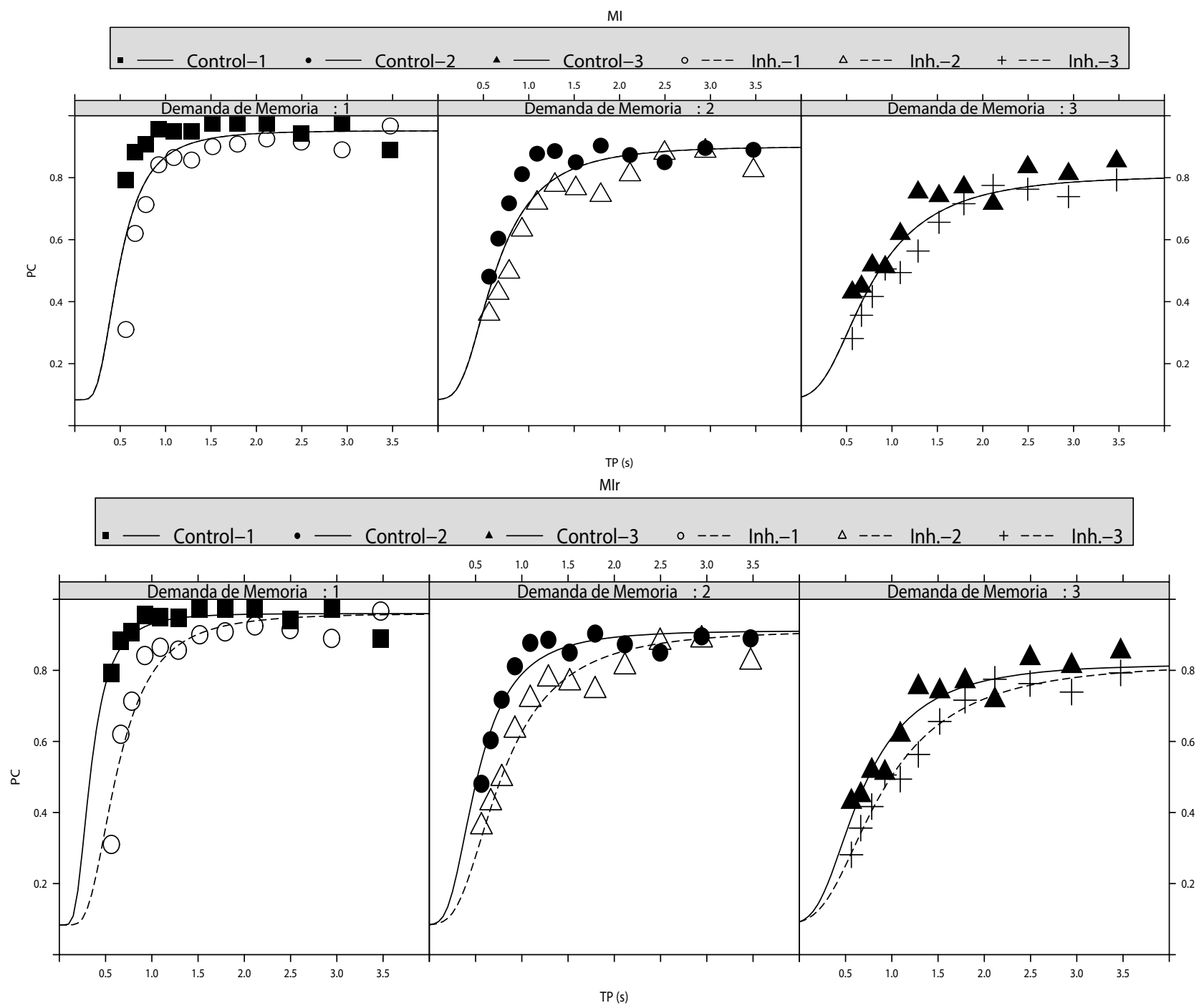

Figura 4. Funciones tiempo-precisión promediadas por demanda de memoria y condiciones experimentales. Datos son representados por los símbolos. Líneas indican las predicciones del MI - panel superior - y del MIr - panel inferior. PC $=$ proporción de respuestas correctas; $\mathrm{TP}=$ tiempo de presentación en segundos; Control = condición control; Inh. $=$ condición inhibición.

clave contextual (Oberauer \& Kliegl, 2006). Además, este modelo asume que el parámetro $\sigma$ refleja dificultades seleccionando la representación apropiada al incrementar la competencia por ser activadas en la capa del foco atencional (Oberauer \& Kliegl, 2006). También, se encontró evidencia adicional respecto al presupuesto de que desplazar el foco de atención de una representación a otra consume tiempo (Garavan, 1998; Oberauer, 2003; Oberauer \& Kliegl, 2006). Los parámetros $r_{\text {ContrDM >2 }} \mathrm{y} r_{\text {InhiDM }>2}$ apoyan las hipótesis de que en ambas condiciones experimentales la velocidad de procesamiento decrece cuando la demanda de memoria incrementa de uno a dos estímulos.

Respecto a la velocidad de procesamiento entre condiciones experimentales, el estimado negativo del parámetro $r_{\text {Inbi.Contr. }}$ indicó que los pasos de actualización en la condición inhibición requieren más tiempo que en la condición control (ver panel inferior 
de la Figura 4). Estos hallazgos insinúan un escenario en como el desplazamiento de la atención entre tareas (para una revisión ver Monsell, 2003) y la inhibición de respuestas dominantes (Friedman \& Miyake, 2004; Hasher, Zacks \& May, 1999) están relacionados con la memoria de trabajo.

En este experimento los participantes tenían que desplazar la atención entre dos tipos de tareas: mover mentalmente el estímulo una casilla en la dirección señalada por la flecha negra o mover mentalmente el estímulo en la dirección opuesta a la señalada por flecha blanca. Por un lado, la teoría detrás de los paradigmas de cambio de tarea sugiere una reducción de la velocidad de procesamiento en la condición inhibición debido al tiempo que consume desplazar la atención entre las tareas indicadas por las flechas blancas y las flechas negras. Por otro lado, la tarea indicada por la flecha blanca se incluyó con el fin de crear un conflicto entre la tendencia natural de mover mentalmente un estímulo en la dirección señalada por la flecha versus la respuesta, atípica, de mover un estímulo en la dirección opuesta a la indicada por la flecha. Así, este experimento exhibe un escenario en el que dos funciones ejecutivas reducen la velocidad de actualizar representaciones en memoria de trabajo, lo cual repercute en la cantidad de tiempo necesario para alcanzar el rendimiento máximo promedio de respuestas correctas en funciones de tiempo-precisión.

Finalmente, es importante mencionar que los componentes de la varianza del MIr no incluyeron el cero en sus intervalos de confianza lo que brinda evidencia de diferencias individuales en interferencia por sobre-escritura, interferencia por confusión y velocidad de procesamiento.

\section{Discusión}

Uno de los objetivos de este trabajo es proponer los modelos cognitivos formales como una de las áreas de investigación en las que se vislumbran oportunidades para facilitar una mejor integración de la psicometría en las prácticas de investigación psicológica. Para este fin se implementó y se contrastó un modelo formal de los límites de la capacidad de memoria de trabajo.
Específicamente, se examinó el papel de la inhibición y del desplazamiento de la atención en el marco de un modelo que propone la interferencia por sobreescritura y la interferencia por confusión como los mecanismos que limitan la capacidad de memoria de trabajo. El contexto en el que se modelaron los datos permitirá exponer algunas similitudes entre la teoría de las variables latentes (Markus \& Borsboom, 2013) y los modelos cognitivos formales. Posteriormente, se propone que las teorías en memoria de trabajo se encuentran en un estado de desarrollo que debería verse como una oportunidad para la implementación de nuevos modelos y teorías en psicometría.

\section{La teoría de las variables latentes}

La teoría filosófica de las variables latentes asume que las puntuaciones observadas tienen ruido pero que los atributos psicológicos poseen cierta estructura y que un conjunto de variables observadas dependen estadísticamente de esa estructura. De esta manera, la teoría propone que los valores esperados de una variable observada dependen de una variable latente. Así, con excepción del error de medición los valores esperados de las variables observables son condicionales a la variable latente en cuestión. Producto de esta teoría han surgido varios modelos psicométricos.

En este trabajo, el término "modelos psicométricos" hace referencia a los modelos estadísticos (e.g., la teoría clásica de los tests, la teoría de la generalizabilidad, y las teorías modernas de los tests para detalles ver Markus \& Borsboom, 2013) que generalmente parten de la interpretación de los datos y lo que se busca es el ajuste del modelo respecto a los datos. Ejemplos de modelos psicométricos basados en la teoría de las variables latentes tenemos el análisis de componentes principales, los modelos de ecuaciones estructurales, la teoría de respuesta a los ítems, etc.

El primero de ellos es caracterizado como formativo debido a que, en este modelo psicométrico, los ítems causan parte de la varianza de la variable latente. Los dos últimos, son denominados reflectantes debido a que las variables latentes causan parte de la variabilidad de las puntuaciones de las personas, objetos o eventos 
en un ítem. Aunque ambos modelos psicométricos de causalidad son útiles es el último de ellos quien ofrece una mejor perspectiva para representar la relación entre el atributo teórico y los ítems que lo miden (para detalles ver Markus \& Borsboom, 2013). Por esta razón en la sección siguiente se presentan algunas similitudes entre el enfoque de los modelos cognitivos formales y los modelos psicométricos reflectantes.

Modelos cognitivos formales y el modelopsicométrico reflectante

Los modelos cognitivos formales han sido definidos como una estructura formal que captura patrones en los datos (Luce, 1995) y que son derivados de los principios básicos de la cognición. En general, los modelos cognitivos formales emplean las respuestas observadas para hacer inferencias acerca del proceso cognitivo que les subyace (Forstmann, Wagemakers, Eichele, Brown, $\&$ Serences, 2011). Estas estructuras pueden variar en términos del nivel de profundidad (e.g., desde modelos descriptivos hasta modelos explicativos), en términos del nivel especificidad (e.g., desde modelos específicos o hasta modelos generales) o en términos de si son modelos matemáticos o computacionales (Forstmann, et. al 2011). Por ejemplo el MI, expuesto en este trabajo, caracteriza la forma en la que los objetos mentales son representados en memoria de trabajo, a saber, un patrón de activación de unidades características distribuidas y dispersas (Oberauer \& Kliegl, 2006). Este modelo no es explicativo debido a que no profundiza, por ejemplo, en mecanismos como los procesos de ensayo subarticulatorio (Baddeley, Thomson y Buchanan, 1975; Page y Norris, 1998) o procesos de ensayo vía atención (Camos, Lagner, \& Barrouillet, 2009). EL MI es matemático, en el sentido que no es implementado como una computadora, y el MI es específico debido a que es desarrollado en el contexto de una tarea de actualización de memoria de trabajo y de funciones de tiempo-precisión.

A partir de esta breve descripción se puede decir que los modelos cognitivos formales y el modelo psicométrico reflectante de las variables latentes comparten: a) el objetivo de la especificación formal de los atributos a estudiar; b) el presupuesto de que los datos, en sí mismos, son "mudos" pero que existe una estructura que causa la variación del atributo o proceso cognitivo en cuestión; y c) la asunción de que las respuestas observadas se pueden descomponer en términos de variables latentes.

A pesar de estos puntos de convergencia, en la construcción de modelos psicométricos es deseable que estos no sean altamente específicos al contenido. Así, como muchos de los modelos que son desarrollados, primariamente, desde el punto de vista estadístico, los modelos psicométricos de las variables latentes son genéricos; y con ello, neutrales en términos de contenido. Esto permite a los investigadores usar los modelos psicométricos en campos en donde no hay una teoría formalizada (i.e., dónde las teorías son puramente verbales como es el caso de la mayoría de las teorías en educación y psicología).

De esta manera, son un método que permite adscribir propiedades psicométricas a los ítems pero que no dicen qué se está midiendo (Markus \& Borsboom, 2013). Esta información, en la práctica actual, es proporcionada por el investigador quien interpreta los resultados en el contexto de un dominio teórico particular. Estos lazos débiles entre el modelo psicométrico y el contenido pueden potencialmente traer muchos problemas de validez.

Afortunadamente, esfuerzos recientes en el modelamiento cognitivo moderno de los respuestas a los ítems se han inspirado en teorías de la cognición humana (Embretson, 2010). Por ejemplo, en este enfoque el modelo cognitivo de un test bien desarrollado involucra: la descripción de un proceso que conecta dicho proceso con causalidad; provee una guía para el desarrollo, la modificación y el juzgamiento de los ítems; y expresa el tipo de ítems que no proveen información adicional respecto a su teoría. Siguiendo esta variación del enfoque de las variables latentes se logra establecer un mejor vínculo entre la teoría psicológica y el modelo psicométrico por medio de la minuciosa especificación de los ítems; no obstante, el modelo estadístico sigue siendo genérico.

En el contexto de los modelos cognitivos formales los ítems (i.e., los ensayos) y el modelo matemático 
o estadístico están inspirados fuertemente en una teoría cognitiva. Por ejemplo, una de las condiciones experimentales del presente estudio incluyó ensayos en los que la inhibición de la respuesta inminente y el desplazamiento dela atención entre tareas son necesarios para actualizar una representación en memoria de trabajo. Particularmente, se encontró evidencia de que esta manipulación experimental podría afectar el parámetro $r$. Dicho parámetro, estimado en todas las ecuaciones del MIr, refleja el tiempo promedio para actualizar y recuperar las representaciones (Oberauer \& Kliegl, 2006).

Así, la condición experimental inhibición en comparación con la condición control incluye, adicionalmente, el tiempo que consume la inhibición de una respuesta inminente y el tiempo de desplazar la atención de una tarea a otra. En esta investigación se encontró evidencia a favor del ajuste del MIr con respecto a los datos pertenecientes a ambas condiciones experimentales. Esto nos permite asumir que el tiempo adicional que capturan estos procesos no cambia significativamente las propiedades de la función matemática que el MI especifica para el procesamiento de la información en memoria de trabajo, a saber, una función exponencial negativamente acelerada (ver ecuaciones 2 y 3 ).

Borsboom (2006) sugiere que uno de los aspectos que han obstaculizado la integración de la psicometría en las prácticas de investigación psicológica radica en la ausencia de una teoría psicológica fuerte. Actualmente, dicha aseveración sigue siendo válida en el contexto general de la psicología; sin embargo, muchas áreas de la psicología experimental y en especial aquellas vinculadas con el uso de los modelos cognitivos formales ofrecen excelentes teorías respecto a procesos cognitivos como la memoria de trabajo (Brown, Neath \& Chater, 2007; Farrell \& Lewandowsky, 2002; Oberauer \& Lewandowsky, 2011; Oberauer, Lewandowsky, Farrell, Jarrold, \& Greaves, 2012), el razonamiento (Anderson, Bothell, Byrne, Douglass, Lebiere, et al., 2004), la toma de decisiones rápidas (Ratcliff \& McKoon, 2007) o riesgosas (Wallsten, Pleskac, \& Lejuez, 2011), categorización perceptual (Nosofky, 1986), etc.
En el contexto de los avances científicos respecto al conocimiento de varios procesos cognitivos la sección siguiente sugiere que al menos en el caso del estudio de la capacidad de memoria de trabajo y el estudio de la inteligencia fluida se encuentra un área fértil para la implementación de nuevas teorías y modelos psicométricos.

Capacidad de memoria de trabajo y diferencias individuales en inteligencia fluida

De acuerdo con la teoría de la inversión de Cattell (1987) la inteligencia fluida ha sido relacionada con la capacidad de resolver problemas novedosos y complejos empleando procesos cognitivos como el razonamiento inductivo y deductivo, la formulación de conceptos y la clasificación (Kvist \& Gustaffson, 2008). Usualmente los tests que se han propuesto como indicadores de inteligencia fluida emplean matrices con figuras. Desde la década de los 90 la construcción de los ítems de matrices con figuras ha sido inspirada en teorías cognitivas (Arendasy \& Sommer, 2005, 2013; Carpenter, Just \& Shell, 1990; Embretson, 1995; Primi, 2001).

Aspectos como el número de reglas, la complejidad de las reglas, el nivel de abstracción, entre otros han sido los elementos básicos que constituyen la construcción de los ítems (Arendasy \& Sommer, 2005, 2013; Carpenter, Just \& Shell, 1990; Embretson, 1995; Primi, 2001). Con excepción del número de reglas que está claramente contextualizado en los estudios de la capacidad de memoria de trabajo muchos otros hallazgos no han sido incorporados en el diseño de los estos ítems.

Después de todo, existe evidencia contundente de que el mejor predictor de este tipo de pruebas son aquellas que capturan la capacidad de memoria de trabajo (Engle, et al., 1999; Kyllonen \& Christal, 1990; Palladino, et al. 2001; Schmiedek, Hildebrant, Lövdén, Wilhelm, \& Lindenberger, 2009). También, es inquietante que el conocimiento generado, a partir de un buen grupo de modelos matemáticos de la memoria de trabajo (Brown, Neath \& Chater, 2007; Farrell \& Lewandowsky, 2002; Oberauer \& Lewandowsky, 2011; 
Oberauer, Lewandowsky, Farrell, Jarrold, \& Greaves, 2012), tampoco se halla incorporado naturalmente en el desarrollo de los ítems y en las teorías de inteligencia fluida. Personalmente considero, que los grupos de investigación están muy ocupados en sus propios problemas y dada la separación histórica que ha existido entre la psicometría y la psicología matemática (Borsboom, 2006) no han dado un vistazo al trabajo de sus "vecinos".

Aspectos como la interferencia entre representaciones y el contexto, mecanismos como la inhibición de respuestas inminentes, la flexibilidad cognitiva, los mecanismos de ensayo articulatorio o vía atención, el papel que juega el espacio temporal en la memoria de trabajo (Brown, Neath \& Chater, 2007; Oberauer, Lewandowsky, Farrell, Jarrold, \& Greaves, 2012) y la velocidad de procesamiento en memoria de trabajo merecen más atención a fin de que sean incorporados y contrastados en futuras teorías y modelos psicométricos de la inteligencia fluida.

A modo de conclusión, esta investigación presentó nuevos hallazgos respecto a los límites de la capacidad de memoria de trabajo con el fin de describir detalladamente la estrategia y filosofía detrás de los modelos cognitivos formales para poner en escena algunas similitudes y diferencias con los modelos psicométricos de las variables latentes. A partir de esto se ejemplificó al menos un campo de estudio (i.e., el estudio de la memoria de trabajo) en el que los avances científicos hacen necesario el papel protagónico de ambas disciplinas. La posible integración de estas disciplinas será de mucho beneficio para áreas de conocimiento que emergen a gran velocidad y con necesidad de Teorias Formales (e.g. la neurociencia cognitiva).

\section{Referencias}

Anderson, J. R., \& Lebiere, C. (1998). The atomic components of thought. Mahwah, NJ: Erlbaum.

Anderson, J. R., Bothell, D., Byrne, M. D., Douglass, S., Lebiere, C., \& Qin, Y. (2004). An integrated theory of mind. Psychological Review, 111, 1036-1060.
Arendasy, M. E. \& Sommer, M. (2005). The effect of different types of perceptual manipulations on the dimensionality of automatically generated figural matrices. Intelligence, 33, 307-324.

Arendasy, M. E. \& Sommer, M. (2013). Reducing response elimination strategies enhances the construct validity of figural matrices. Intelligence, 41, 234-243.

Baddeley, A. D., Thomson, N., \& Buchanan, M. (1975). Word length and the structure of short-term memory. Journal of Verbal Learning and Verbal Behavior, 14, 575-589.

Barrouillet, P. \& Camos, V. (2009). Interference: Unique source of forgetting in working memory? Trends in Cognitive Sciences, 13, 145-146.

Borsboom, D. (2006). The attack of psychometricians. Psychometrika, 71, 425-440.

Brown, G. D. A., Neath, I., \& Chater, N. (2007). A ratio model of scale-invariant memory and identification. Psychological Review, 107, 127-181.

Burnham, K. P., \& Anderson, D. R. (2002). Model selection and multimodel inference: A practical information-theoretic approach (2nd ed.). New York; Springer-Verlag.

Camos, V., Lagner, P., \& Barrouillet, P. (2009). Two maintenance mechanisms of verbal information in working memory. Journal of Memory and Language, 61, 457-469.

Carpenter, P.A., Just, M.A., \& Shell, P. (1990). What one intelligence test measures: A theoretical account of processing in the Raven progressive matrices test. Psychological Review, 97, 404- 431 .

Cattell, R.B. (1987). Abilities: Their structures, growth, and actions. New York: North-Holland.

Conrad, R. \& Hull, A. J. (1964). Information, acoustic confusion and memory span. British Journal of Psychology, 55, 75-84. 
Coopeland, D. E., \& Radvansky, G. A. (2001). Phonological similarity in working memory. Memory \& Cognition, 29, 774-776.

Cowan, N. (2001). The magical number 4 in shortterm memory: A reconsideration of mental storage capacity. Behavioral and Brain Sciences, 24(1), 87-185.

Cronbach, L. J., \& Meehl, P. E. (1955). Construct validity in psychological tests. Psychological Bulleting, 52, 281-302.

Embretson, S. E. (1995). The role of working memory capacity and general control processes in intelligence. Intelligence, 20, 169-189.

Embretson, S. E. (2004). The second century of ability testing: Some predictions and speculations. Measurement, 2, 1-32.

Embretson, S. E. (2010). Cognitive design systems: A structural modeling approach applied to developing a spatial ability test. In S. E. Embretson (Ed.), Measuring psychological constructs: Advances in model-based approaches (pp. 247-273). Washington, DC: American Psychological Association.

Engle, R. W., Tuholski, S. W., Laughlin, J. E., \& Conway, A. R. A. (1999). Working memory, shortterm memory and general fluid intelligence: A latent variable approach. Journal of Experimental Psychology: General, 128, 309-331.

Farrell, S. \& Lewandowsky, S. (2002). An endogenous distributed model of ordering in serial recall. Psychonomic Bulletin \& Review, 9, 59-79.

Forstmann, B. U., Wagenmakers, E-J., Eichele, T., Brown, S., \& Serences, J. T. (2011). Reciprocal relations between cognitive neuroscience and formal cognitive models: Opposites attract? Trends in Cognitive Sciences, 15, 272-279.

Friedman, N. P. \& Miyake, A. (2004). The relations among inhibition and interference cognitive functions: A latent variable analysis. Journal of Experimental Psychology: General, 133, 101-135.

Garavan, H. (1998). Serial attention within working memory. Memory \& Cognition, 26, 263-276.
Hasher, L., Zacks, R. T., \& May, C. P. (1999). Inhibitory control, circadian arousal, and age. In D. Gopher \& A. Koriat, (Eds.), Attention and performance XVII: Cognitive regulation of performance: Interaction of theory and application (pp. 653-675). Cambridge, MA: MIT Press.

Kvist, A., V. \& Gustafsson, J-E. (2008). The relation between fluid intelligence and the general factor as a function of cultural background: A test of Cattell's Investment theory. Intelligence, 36, 422-436.

Kyllonen, P. C., \& Christal, R. E. (1990). Reasoning ability is (little more than) working-memory capacity? Intelligence, 14, 389-433.

Lewandowsky, S., Oberauer, K., \& Brown, G. D. A. (2009). Response to Barrouillet and Camos: Interference or decay in working memory. Trends in Cognitive Sciences, 13, 146-147.

Lobley, K. J., Baddeley, A. D., \& Gathercole, S. E. (2005). Phonological similarity effect in verbal complex span. Quarterly Journal of Experimental Psychology, 58A, 1464-1478.

Luce, R. D. (1995). Four tensions concerning mathematical modeling in psychology. Annual Review of Psychology, 46, 1-26.

Markus, K. A. \& Borsboom, D. (2013). Frontiers of test validity theory. Measurement, causation, and meaning. NY: Routledge.

McClelland, J. L. (1979). On the time relations of mental processes: an examination of systems of processes in cascade. Psychological Review, 86, 287-330.

McElree, B., \& Dosher, B. A. (1989). Serial position and set size in short-term memory: the time course of recognition. Journal of Experimental Psychology: General, 118, 346-373.

Messick, S. (1989). Validity. In R. L. Linn (Ed.), Educational measurement (pp. 13103). Washington, DC: American Council on Education and National Council on Measurement in Education. 
Miyake, A., Friedman, N. P., Emerson, M. J., Witzki, A. H., \& Howerter, A. (2000). The unity and diversity of the executive functions and their contributions to complex "frontal lobe" tasks: A latent variable analysis. Cognitive Psychology, 41, 49-100.

Monsell, S. (2003). Task switching. Trends in Cognitive Sciences, 7, 134-140.

Nairne, J. S. (1990). A feature model of immediate memory. Memory \& Cognition, 18(3), 251-269.

Nosofky, R. M. (1986). Attention, similarity, and the identification-categorization relationship. Journal of Experimental Psychology: General 115, 39-61.

Oberauer, K. (2003). Selective attention to elements in working memory. Experimental Psychology, 50(4), 257-269.

Oberauer, K., \& Kliegl, R. (2006). A formal model of capacity limits in working memory. Journal of Memory and Language, 55(4), 601-626.

Oberauer, K. \& Lewandowsky, S. (2011). Modeling working memory: A computational implementation of the Time-Based ResourceSharing theory. Psychonomic Bulletin \& Review, 18, 10-45.

Oberauer, K., \& Lewandowsky, S., Farrell, S., Jarrold, C. \& Greaves, M. (2012). Modeling working memory: An interference model of complex span. Psychonomic Bulletin \& Review, 19, 779-819.

Pages, M. P. A. \& Norris, D. (1998). The primacy model: A new model of immediate serial recall. Psychological Review, 105, 761-781.

Palladino, P., Cornoldi, C., De Beni, R., \& Pazzaglia, F. (2001). Working memory and updating processes in reading comprehension. Memory \& Cognition, 29(2), 344-354.

Primi, R. (2001). Complexity of geometric inductive reasoning tasks. Contribution to the understanding of fluid intelligence. Intelligence 30(1), 41-70.

Psychometric Society. (2015). What is psychometrics? Retrieved from https://www.psychometricsociety. org/content/what-psychometrics

Ratcliff, R. \& McKoon, G. (2007). The diffusion decision model: Theory and data for two-choice decision task. Neural Computation, 20, 873-922.

Schmiedek, F., Hildebrandt, A., Lövdén, M., Wilhelm, O., \& Lindenberger, U. (2009). Complex span versus updating tasks of working memory: The gap is not that deep. Journal of Experimental Psychology: Learning, Memory, and Cognition, 35, 1089-1096.

Schneider, W., Eschman, A., \& Zuccolotto, A. (2002). E-Prime user's guide. Pittsburgh: Psychology Software Tools, Inc.

Usher, M., \& McClelland, J. L. (2001). The time course of perceptual choice: The leaky, competing accumulator model. Psychological Review, 108, 550-592.

Venables, W. N., \& Ripley, B. D. (2002). Modern Applied Statistics with S (4th ed.). New York: Springer-Verlag.

Wallsten, T. S., Pleskac, T. J., \& Lejuez, C. W. (2011). Modeling behaviour in a clinical diagnostic sequential risk-taking task. Psychological Review, 112, 862-880.

Wasserman, L. (2000). Bayesian model selection and model averaging. Journal of Mathematical Psychology, 44, 92-107.

Recibido: 21 de abril de 2015 Aceptado: 9 de setiembre de 2015 